\title{
Stratification of Prognosis in Patients With Ampullary Carcinoma After Surgery by Preoperative Platelet-to- lymphocyte Ratio and Conventional Tumor Markers
}

\author{
HIROMICHI KAWAIDA ${ }^{1}$, HIROSHI KONO ${ }^{1}$, HIDETAKE AMEMIYA ${ }^{1}$, NAOHIRO HOSOMURA ${ }^{1}$, \\ MITSUAKI WATANABE ${ }^{1}$, RYO SAITO ${ }^{1}$, SUGURU MARUYAMA ${ }^{1}$, HIROKI SHIMIZU $^{1}$, SHINJI FURUYA ${ }^{1}$, \\ HIDENORI AKAIKE ${ }^{1}$, YOSHIHIKO KAWAGUCHI ${ }^{1}$, MAKOTO SUDO ${ }^{1}$, MASANORI MATUSDA ${ }^{1}$, JUN ITAKURA ${ }^{1}$, \\ HIROKO SHINDO ${ }^{2}$, EI TAKAHASHI ${ }^{2}$, SHINICHI TAKANO ${ }^{2}$, MITSUHARU FUKASAWA ${ }^{2}$, TADASHI SATOU ${ }^{2}$, \\ TADAO NAKAZAWA ${ }^{3}$, NOBUYUKI ENOMOTO ${ }^{2}$, HIDEKI FUJII $^{1}$ and DAISUKE ICHIKAWA ${ }^{1}$ \\ ${ }^{1}$ First Department of Surgery, Faculty of Medicine, University of Yamanashi, Yamanashi, Japan; \\ ${ }^{2}$ First Department of Internal Medicine, Faculty of Medicine, University of Yamanashi, Yamanashi, Japan; \\ ${ }^{3}$ Department of Human Pathology, Faculty of Medicine, University of Yamanashi, Yamanashi, Japan
}

\begin{abstract}
Background/Aim: The platelet-to-lymphocyte ratio (PLR) has recently been suggested as a new predictor of the prognosis in several carcinoma types. However, the clinical impact remains controversial in patients with ampullary carcinoma. Thus, the aim of this study was to investigate other useful biomarkers for identifying poor prognosis in patients with ampullary carcinoma. Patients and Methods: Forty-one patients with ampullary carcinoma underwent pancreaticoduodenectomy (PD) with curative resection between April 2000 and April 2017. Various clinicopathological findings of the patients and their tumors were evaluated as potential prognostic factors which might enable better stratification of prognosis. Results: Platelet-to-lymphocyte ratio, as well as other markers, was found to be a prognostic factor in patients with ampullary carcinoma. The 2-year disease-free survival percentage was significantly higher in the group with low PLR than in the high PLR group (70.2\% vs. 28.6\%; p=0.005). Combinational analysis of the PLR and conventional TMs enabled us to stratify prognosis of the patients more clearly than by each marker alone. Conclusion: PLR was a useful prognostic factor for patients with ampullary cancer. The combination of preoperative PLR and conventional TMs markers may be powerful predictive factors for postoperative prognosis in patients with ampullary carcinoma following $P D$.
\end{abstract}

Correspondence to: Hiromichi Kawaida, MD, Ph.D., First Department of Surgery, Faculty of Medicine, University of Yamanashi, 1110 Shimokato, Chuo, Yamanashi, 409-3898 Japan. Tel/Fax: +81 0552737390, e-mail: kawaidah@yamanashi.ac.jp

Key Words: Platelet-to-lymphocyte ratio, tumor marker, ampullary carcinoma, biomarkers, poor prognosis.
Ampullary carcinoma is extremely rare, accounting for approximately $0.2-0.5 \%$ of all gastrointestinal malignancies and approximately $6-17 \%$ of periampullary tumors (1-4). The most commonly recommended treatment is pancreaticoduodenectomy (PD), which has a reported resectability rate of $82.1 \%$ (1). Although ampullary carcinoma is considered to have a better prognosis [5-year survival rate of $30 \%$ to $60 \%(1,5,6)$ ] than other peripancreatic head adenocarcinomas, some cases have a poor prognosis with early recurrence.

Several prognostic factors have been reported in ampullary carcinoma, including lymph node metastasis (1, $7-10)$, depth of tumor infiltration $(2,9)$, tumor stage $(3,10)$, involvement of resection margins (5), lymphatic vessel invasion (7), perineural invasion (8), and pancreaticobiliary subtype $(4,10,11)$. However, accurate information for these factors are generally obtained postoperatively.

In recent years, biomarkers have been suggested as new prognostic factors in several cancer types. Of these, the lymphocyte-to-monocyte ratio (LMR), neutrophil-tolymphocyte ratio (NLR), and platelet-to-lymphocyte ratio (PLR) have been studied extensively and adopted as predictors of prognosis in other diseases (12-25). However, in ampullary carcinoma, the roles of these biomarkers remain controversial, as the presence of this disease is relatively rare and blood-based biomarkers may be affected by comorbidities, such as obstructive jaundice and cholangitis.

Based on this, we evaluated preoperative LMR, NLR, and PLR as prognostic factors for ampullary carcinoma in patients free of obstructive jaundice and cholangitis. Furthermore, in order to better stratify groups based on prognosis, we examined whether the combination of these blood-based biomarkers and conventional TMs would act as prognostic factors for ampullary carcinoma. 


\section{Patients and Methods}

Patients. We examined 41 patients with ampullary carcinoma who underwent PD with curative resection at the First Department of Surgery at Yamanashi University, between April 2000 and April 2017.

Clinical characteristics, preoperative laboratory data, postoperative complications, and pathological examinations were collected from patient's electronic medical records. Preoperative data, including serum TMs carcinoembryonic antigen (CEA), carbohydrate antigen 19-9 (CA19-9) and Duke pancreatic monoclonal antigen type 2 (DuPAN-2), were collected within 2 weeks of surgery. Additionally, total bilirubin, white blood cell (WBC) count, and C-reactive protein (CRP) values were confirmed to be within normal reference values, as these may have affected the LMR, NLR, and PLR. From these data, we calculated the LMR, NLR, and PLR. To supplement the perioperative data, a review of the surgical and anesthetic charts of each patient was carried out. Histopathological examination was performed after surgery. We used the TNM classification of Malignant Tumors Eighth Edition edited by the Union for International Cancer Control for determining the TNM stage (26). As cases with recurrence within 2 years have extremely poor prognosis, the patients were divided into two groups: i) Non-early recurrence group, patients without recurrence within 2 years (non-ER group); 2) early recurrence group, patients with recurrence within 2 years (ER group). Patient characteristics are shown in Table I.

Adjuvant treatment. The patients with T3/lymph node metastasis routinely received chemotherapy, except for those with renal dysfunction and three patients who did not agree to the treatment.

The main regimens were intravenous gemcitabine $\left(1000 \mathrm{mg} / \mathrm{m}^{2}\right)$ on days 1,8 , and 15 every 4 weeks ( 1 cycle) for up to six cycles, and intravenous gemcitabine $\left(1000 \mathrm{mg} / \mathrm{m}^{2}\right)$ plus cisplatin $\left(25 \mathrm{mg} / \mathrm{m}^{2}\right)$ on days 1 and 8 every 3 weeks ( 1 cycle) for up to eight cycles. Four patients chose orally administered S-1 (TS-1; Taiho Pharmaceutical, Tokyo, Japan), at $40 \mathrm{mg}, 50 \mathrm{mg}$, or $60 \mathrm{mg}$ based on body surface area, twice a day for 28 days followed by a 14-day rest (1 cycle) for up to four cycles after surgery, because frequent visits were difficult.

Patient follow-up. TM analysis was examined monthly, and computed tomography was performed every 3 months. Recurrence was diagnosed based on imaging findings or continuous rise of TMs.

Statistical analysis. TMs were classified as within or beyond the reference value, and biomarkers were expressed as the mean \pm standard deviation. Patient characteristics and preoperative/intraoperative data between the two groups were compared using chi-squared test, Fisher's exact test, and Mann-Whitney $U$-test. The cutoff values for clinical characteristics were determined using receiver operating characteristics (ROC) curve analysis. The recommended cutoff values for the characteristics were defined using the most prominent point on the ROC curve. Disease-free survival (DFS) was calculated as the time from the date of surgery to the date of first recurrence. Overall survival (OS) was calculated as the time from the date of surgery to the date of death from any cause or last follow-up. DFS and OS were estimated using the Kaplan-Meier method. Significance was defined as a $p<0.05$. The statistical analyses were performed using SPSS version 23.0 software (IBM, Armonk, NY, USA).
Table I. Characteristics of patients according to recurrence within 2 years.

\begin{tabular}{|c|c|c|c|}
\hline & \multicolumn{2}{|c|}{ Recurrence within 2 years } & \multirow[b]{2}{*}{$p$-Value } \\
\hline & No $(n=23)$ & Yes $(n=18)$ & \\
\hline \multicolumn{4}{|l|}{ Gender } \\
\hline Male & 13 & 13 & 0.312 \\
\hline Female & 10 & 5 & \\
\hline \multicolumn{4}{|l|}{ Age } \\
\hline Mean \pm SD & $70.8 \pm 1.4$ & $67.6 \pm 2.9$ & 0.287 \\
\hline \multicolumn{4}{|c|}{ Tumor markers, $\mathrm{n}^{\ddagger}$} \\
\hline Within range & 15 & 6 & 0.084 \\
\hline Beyond range & 8 & 12 & \\
\hline \multicolumn{4}{|c|}{ Operative time, $\min$} \\
\hline Mean \pm SD & $463 \pm 19$ & $478 \pm 20$ & 0.577 \\
\hline \multicolumn{4}{|l|}{ Blood loss, ml } \\
\hline Mean \pm SD & $833 \pm 100$ & $811 \pm 134$ & 0.895 \\
\hline \multicolumn{4}{|c|}{ Blood transfusion, $\mathrm{n}$} \\
\hline Yes & 7 & 7 & 0.582 \\
\hline No & 16 & 11 & \\
\hline \multicolumn{4}{|l|}{ TNM, n* } \\
\hline $\mathrm{T} 1 \mathrm{a}, \mathrm{b}, 2$ & 19 & 6 & $<0.001$ \\
\hline $\mathrm{T} 3$ & 4 & 12 & \\
\hline No & 19 & 8 & 0.008 \\
\hline $\mathrm{N} 1,2$ & 4 & 10 & \\
\hline \multicolumn{4}{|l|}{ POPF, $\mathrm{n}$} \\
\hline Yes & 5 & 5 & 0.665 \\
\hline No & 18 & 13 & \\
\hline \multicolumn{4}{|c|}{ Biomarkers, mean \pm SD } \\
\hline LMR & $4.4 \pm 0.3$ & $3.8 \pm 0.4$ & 0.354 \\
\hline NLR & $2.6 \pm 0.2$ & $3.4 \pm 0.5$ & 0.114 \\
\hline PLR & $170.5 \pm 8.8$ & $255.8 \pm 28.21$ & 0.003 \\
\hline \multicolumn{4}{|c|}{ Adjuvant chemotherapy, $n$} \\
\hline Yes & 4 & 9 & 0.026 \\
\hline No & 19 & 9 & \\
\hline
\end{tabular}

POPF: Postoperative pancreatic fistula; LMR: lymphocyte-to-monocyte ratio, NLR: neutrophil-to-lymphocyte ratio, PLR: platelet-to-lymphocyte ratio. *Union for International Cancer Control, 8th edition (26). $¥$ Carcinoembryonic antigen, carbohydrate antigen 19-9 and Duke pancreatic monoclonal antigen type 2 .

\section{Results}

Patient characteristics. Table I shows the comparison between the non-ER group and the ER group. Preoperative PLR was significantly higher in the ER group, although there was no significant difference in other preoperative blood markers, such as LMR and NLR. With the exception of PLR, T-stage and lymph node metastasis were found to be significant prognostic factors in this cohort. However, there was no significant difference in sex, age, intraoperative findings, and presence or absence of postoperative pancreatic fistula between groups with and without recurrence and nonrecurrent groups. TMs tended to be higher in the early recurrence group, but there was no significant difference between the two groups. 


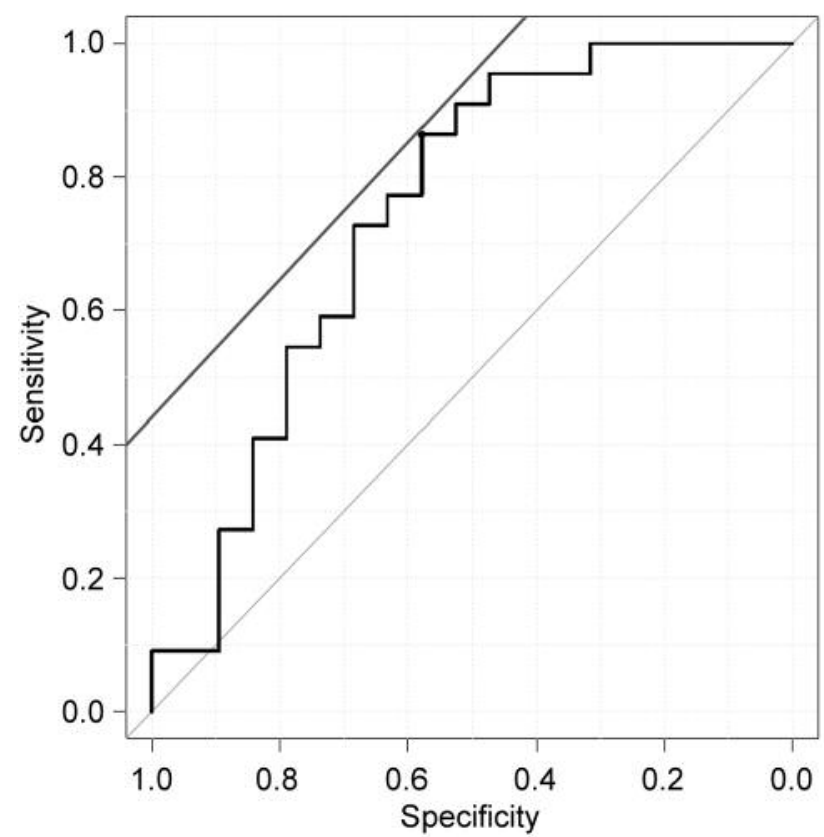

Figure 1. Receiver operating characteristics curve analysis curve for recurrence within 2 years. The optimal cut-off value was for the plateletto-lymphocyte ratio was 211.7, with an area under the curve of 0.744 .

Comparison between the low PLR group and the high PLR group. According to the ROC curve analysis, the optimal cutoff value was 211.7 (Figure 1). Based on the cutoff value, patients were classified into a low PLR group (PLR s211.7) and a high PLR group (PLR >211.7), and clinicopathological findings were compared. There were no significant differences in sex, intraoperative findings, and presence or absence of postoperative pancreatic fistula. However, the high PLR group had significantly more advanced tumors $(p=0.002)$ and tended to have a slightly greater lymph node metastasis than the low PLR group, although not significant $(p=0.130)$. The recurrence rate was significantly higher in the high PLR group $(p=0.010$; Table II).

Impact of the combination of preoperative PLR and TMs as a prognostic factor. In the low PLR group, the 1-year and 2year DFS were $81.5 \%$ and $70.2 \%$, respectively, and those in the high PLR group were $57.1 \%$ and $28.6 \%$, respectively. There was a significant difference between the two groups $(p=0.005$; Figure 2A).

One-year and 2-year DFS in those with TMs falling within the reference values (low TM group) were $85.7 \%$ and $71.1 \%$ respectively, and for those with TMs above the reference value (high TM group) were $60.0 \%$ and $40.0 \%$, respectively $(p=0.043$; Figure 2B).
Table II. Patient characteristics and relationship of recurrence within 2 years according to platelet-to-lymphocyte ratio (PLR).

\begin{tabular}{|c|c|c|c|}
\hline & $\begin{array}{c}\mathrm{PLR} \leq 211.7 \\
(\mathrm{n}=27)\end{array}$ & $\begin{array}{c}\text { PLR }>211.7 \\
\quad(n=14)\end{array}$ & $p$-Value \\
\hline \multicolumn{4}{|l|}{ Gender } \\
\hline Male & 16 & 10 & \multirow[t]{2}{*}{0.456} \\
\hline Female & 11 & 4 & \\
\hline \multicolumn{4}{|l|}{ Age } \\
\hline Mean \pm SD & $71.3 \pm 1.5$ & $65.6 \pm 3.2$ & 0.073 \\
\hline \multicolumn{4}{|c|}{ Tumor markers, $\mathrm{n}^{\ddagger}$} \\
\hline Within range & 14 & 7 & \multirow[t]{2}{*}{0.913} \\
\hline Beyond range & 13 & 7 & \\
\hline \multicolumn{4}{|c|}{ Operative time, $\min$} \\
\hline Mean \pm SD & $460 \pm 17$ & $489 \pm 23$ & 0.316 \\
\hline \multicolumn{4}{|l|}{ Blood loss, ml } \\
\hline Mean \pm SD & $848 \pm 99$ & $719 \pm 125$ & 0.437 \\
\hline \multicolumn{4}{|c|}{ Blood transfusion, $\mathrm{n}$} \\
\hline Yes & 11 & 3 & \multirow[t]{2}{*}{0.226} \\
\hline No & 16 & 11 & \\
\hline \multicolumn{4}{|l|}{ TNM, $\mathrm{n}^{*}$} \\
\hline $\mathrm{T} 1 \mathrm{a}, \mathrm{b}, 2$ & 21 & 4 & \multirow[t]{2}{*}{0.002} \\
\hline $\mathrm{T} 3$ & 6 & 10 & \\
\hline No & 20 & 7 & \multirow[t]{2}{*}{0.13} \\
\hline $\mathrm{N} 1,2$ & 7 & 7 & \\
\hline \multicolumn{4}{|l|}{ POPF, $\mathrm{n}$} \\
\hline Yes & 7 & 3 & \multirow[t]{2}{*}{0.758} \\
\hline No & 20 & 11 & \\
\hline \multicolumn{4}{|c|}{ Recurrence within 2 years, $\mathrm{n}$} \\
\hline Yes & 8 & 10 & \multirow[t]{2}{*}{0.01} \\
\hline No & 19 & 4 & \\
\hline
\end{tabular}

POPF: Postoperative pancreatic fistula. *Union for International Cancer Control, 8th edition (26). ¥Carcinoembryonic antigen, carbohydrate antigen 19-9 and Duke pancreatic monoclonal antigen type 2 .

Further prognostic analysis was performed by dividing all patients into the three following groups according to preoperative PLR and TMs: Group 1: Patients with both low PLR and low TMs $(n=14)$; group 2: patients with either high PLR or high TMs $(n=20)$; and group 3: patients with both high PLR and high TMs $(n=7)$. One-year DFS was $92.3 \%$, $71.4 \%$, and $42.9 \%$, respectively, and 2-year DFS was $84.6 \%$, $52.4 \%$, and $14.3 \%$, respectively ( $p=0.003$; Figure 3 ). Out of all the groups, group 3 showed the worst prognosis. Notably, in group 3, six out of seven cases had recurrent tumors within 2 years $(85.7 \%)$, and the remaining patient also had recurrent tumors 27 months after surgery.

\section{Discussion}

Various inflammatory markers, including LMR, NLR, and PLR, have been identified and evaluated as prognostic factors for several gastrointestinal malignancies, including esophageal squamous cell carcinoma (12, 13), adenocarcinoma of the esophagogastric junction (14), gastric 


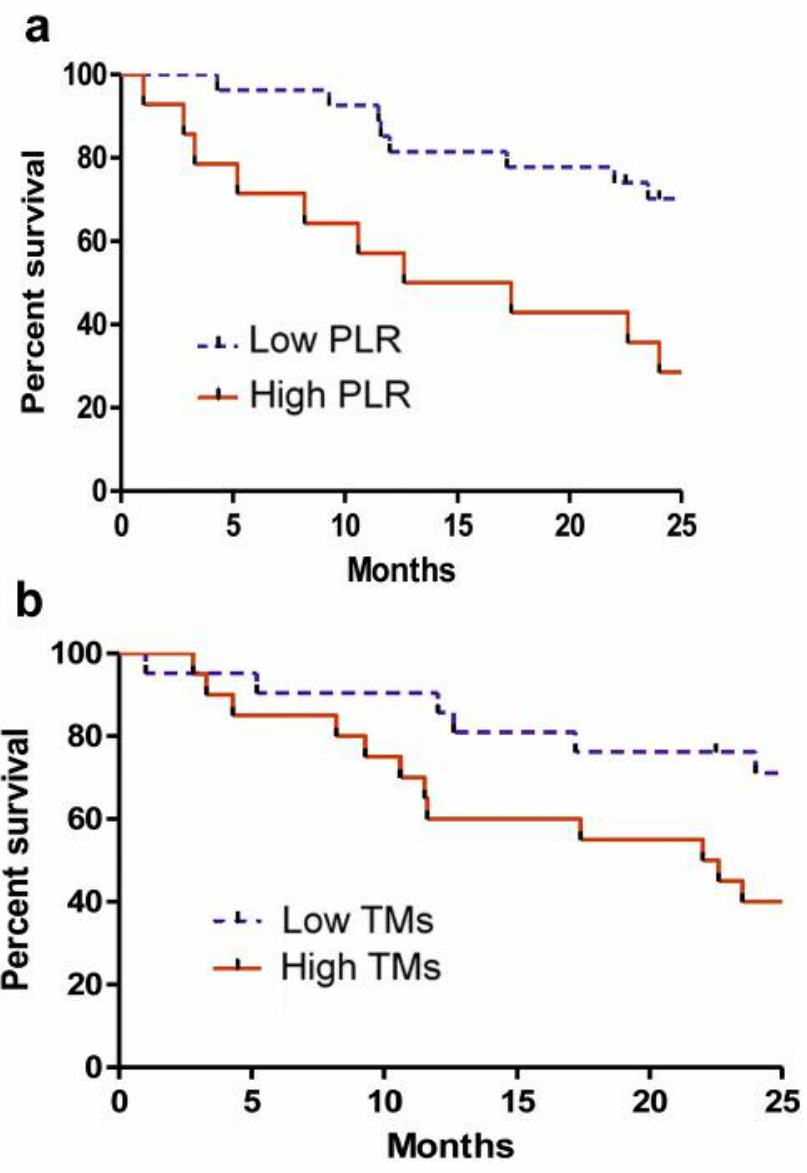

Figure 2. The 2-year disease-free survival (DFS) rates according to platelet-to-lymphocyte ratio (PLR) (A) and aberrant levels of tumor markers (TMS) (B). Those with a low PLR ( $p=0.005)$, and those with low TM levels $(p=0.043)$ had significantly better DFS.

cancer $(15,16)$, colorectal cancer $(17,18)$, perihilar cholangiocarcinoma (19), and pancreatic cancer (20-25). These are clinically common hematological markers for evaluating the inflammatory response in patients with carcinoma because they are relatively easy to examine prior to surgery and have no adverse effects on treatment. However, in patients with ampullary carcinoma, the usefulness of these markers is still controversial, as obstructive jaundice or cholangitis may affect the peripheral blood. Therefore, we evaluated biomarkers when total bilirubin, WBC count, and CRP were within the normal reference values, indicating that patients were not affected by jaundice or cholangitis.

A recent study on gastric adenocarcinoma defined early recurrence as recurrence within 2 years following surgery and concluded that, within the first 2 years, patients should be carefully monitored for distant metastasis (27-29). Therefore, this definition was also used in this study.

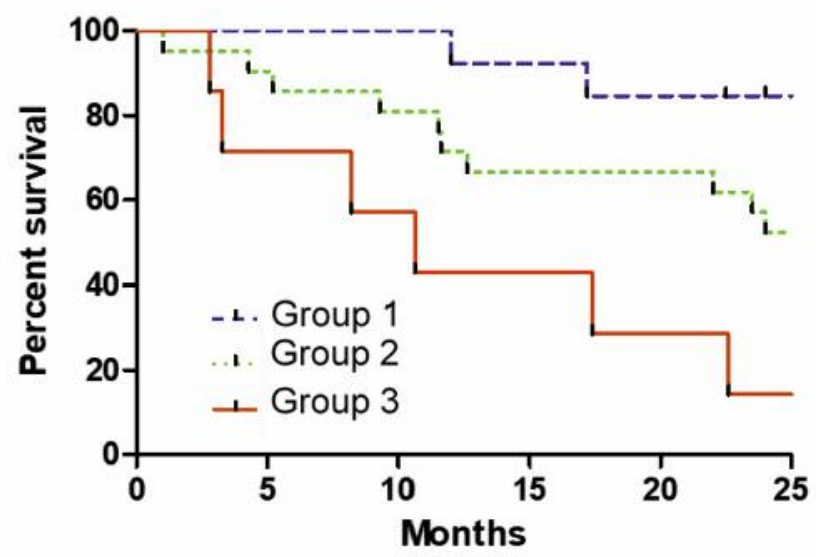

Figure 3. The patients were divided into three groups according to the platelet-to-lymphocyte ratio (PLR) and levels of tumor markers (TMs). Group 1: Both PLR and TMs were low; group 2: either high PLR or high TMs; group 3: high PLR and high TMs. DFS rates of groups 1, 2 and 3 at 1 year were $92.3 \%, 71.4 \%$ and $42.9 \%$, respectively and 2 years were $84.6 \%, 52.4 \%, 14.3 \%$, respectively $(p<0.003)$.

The main finding of the study demonstrates that a preoperative PLR $\geq 211.7$ is an independent predictor of poor postoperative DFS for patients with ampullary carcinoma undergoing radical PD treatment. Another important finding was that the T-stage was advanced in the group with high PLR compared with the low PLR group. However, there was no significant difference between groups in regard to lymph node metastasis. This result suggests that the preoperative PLR correlates in all patients with evidence of local invasion of the resected ampullary carcinoma; this finding is consistent with previous reports (30-32).

Another point of this study is that the combination of preoperative high PLR and high TMs exhibited superior prediction of poor prognosis for patients with resected ampullary carcinoma. In our study, out of the seven cases who had high levels of both PLR and TMs, six (85.7\%) had recurrent tumors within 2 years. Several studies described that combination of PLR and CA19-9 is a prognostic factor in ampullary carcinoma $(30,31)$. However, these studies included patients who had jaundice, which would artificially increase the value of CA19-9. Furthermore, a low CA19-9 value can be a false-negative finding in patients with the Lewis blood-negative group phenotype. Therefore, it may be useful to evaluate CA19-9 along with other TMs .

Invasive tumor causes tissue damage adjacent to the tumor, which results in both a local and systemic chronic inflammatory response (10). Cancer-related inflammation increases regulatory T-cells and activating chemokines which causes the suppression of antitumor immunity. Transforming growth factor beta (TGF $\beta$ ), interleukin (IL)-10, and other inhibitory cytokines secreted by inflammatory cells can depress 
lymphocyte function and reduce circulating lymphocyte counts (33). Conversely, thrombocytosis appears to be stimulated by cancer-related production of cytokines, mainly IL1, IL3, IL6, IL9, and granulocyte-macrophage colony stimulating factor $(34,35)$. These results suggest that PLR may reflect tumorrelated host systemic immune responses. While the most suitable cutoff value of PLR is unknown, the values reported here are similar to those of previous report (32).

In ampullary cancer, the current study showed that the recurrence rate was approximately $35 \%$, and median time to recurrence was 15.3 months in such patients (9). Several adjuvant chemotherapies (e.g. gemcitabine) have been attempted as treatments for patients with ampullary carcinoma, the efficacy of which is controversial (36-39). However, the efficacy of the neoadjuvant chemotherapy has been reported for many gastrointestinal cancer types (40-44). In ampullary carcinoma, the efficacy of neoadjuvant chemotherapy remains controversial $(45,46)$ but it may be considered as one of the therapeutic strategies for patients with poor prognosis. Furthermore, the stratification of patients based on the results of this investigation may be useful for determining the best treatment strategy in ampullary carcinoma. Aside from surgery, ampullary carcinoma still does not have established treatment recommendations. Thus, more aggressive multidisciplinary treatment for patients with ampullary carcinoma should be established, especially for patients at a high risk of poor prognosis; moreover, the results of this study may be useful for determining which patients will likely exhibit the poorest prognosis.

\section{Conclusion}

Measurement of the PLR has been shown to serve as a clinically accessible and useful biomarker for patient outcomes in patients with ampullary cancer, and the combination of high preoperative PLR and high TMs led to even greater predictive power regarding prognosis. In this investigation, patients with resected ampullary carcinoma with the combination of a high preoperative PLR and high TMs exhibited the poorest postoperative prognosis.

\section{Conflicts of Interest}

The Authors declare that they have no conflicts of interest in regard to this study.

\section{Authors' Contributions}

Hiromichi Kawaida was actively involved in this study, especially in terms of statistical design. Seven surgeons (Hiromichi Kawaida, Naohiro Hosomura, Hidetake Amemiya, Hiroshi Kono, Jun Itakura, Hideki Fujii, and Daisuke Ichikawa) contributed to the concept and clinical design. Pathological examination of tissues was performed by Tadao Nakazawa. Acquisition of data was carried out by all physicians. Interpretation of data and drafting of the article was performed by Hiromichi Kawaida. Finally, this article was revised and approved by all 23 investigators. Thus, all 23 Authors actively participated in this study.

\section{Ethics Approval}

This study was approved by the Ethics Committee of Faculty of Medicine, University of Yamanashi (H30108).

\section{References}

1 Howe JR, Klimstra DS, Moccia RD, Conlon KC and Brennan MF: Factors predictive of survival in ampullary carcinoma. Ann Surg 228(1): 87-94, 1998. PMID: 9671071. DOI:10.1097/ 00000658-199807000-00013

2 Qiao QL, Zhao YG, Ye ML, Yang YM, Zhao JX, Huang YT and Wan YL: Carcinoma of the ampulla of Vater: factors influencing long-term survival of 127 patients with resection. World J Surg 31(1): 137-143, 2007. PMID: 17171495. DOI:10.1007/s00268006-0213-3

3 Kim RD, Kundhal PS, McGilvray ID, Cattral MS, Taylor B, Langer B, Grant DR, Zogopoulos G, Shah SA, Greig PD and Gallinger S: Predictors of failure after pancreaticoduodenectomy for ampullary carcinoma. J Am Coll Surg 202(1): 112-119, 2005. PMID: 16377504. DOI: 10.1016/j.jamcollsurg.2005.08.002

4 Okano K, Oshima M, Yachida S, Kushida Y, Kato K, Kamada H, Wato M, Nishihira T, Fukuda Y, Maeba T, Inoue H, Masaki T and Suzuki Y: Factors predicting survival and pathological subtype in patients with ampullary adenocarcinoma. J Surg Oncol 110(2): 156-162, 2014. PMID: 24619853. DOI: $10.1002 /$ jso.23600

5 Allema JH, Reinders ME, van Gulik TM, van Leeuwen DJ, Verbeek PC, de Wit LT, Gouma DJ: Results of pancreaticoduodenectomy for ampullary carcinoma and analysis of prognostic factors for survival. Surgery 117(3): 247-253, 1995. PMID: 7878528. DOI: 10.1016/s0039-6060(05)80197-7

6 Lemke J, Schäfer D, Sander S, Henne-Bruns D and Kornmann M: Survival and prognostic factors in pancreatic and ampullary cancer. Anticancer Res 34(6): 3011-3020, 2014. PMID: 24922667.

7 Klein F, Jacob D, Bahra M, Pelzer U, Puhl G, Krannich A, Andreou A, Gül S and Guckelberger O: Prognostic factors for long-term survival in patients with ampullary carcinoma: the results of a 15-year observation period after pancreaticoduodenectomy. HPB Surg 2014: 970234, 2014. PMID: 24723741. DOI: $10.1155 / 2014 / 970234$

8 Lazaryan A, Kalmadi S, Almhanna K, Pelley R and Kim R: Predictors of clinical outcomes of resected ampullary adenocarcinoma: a single-institution experience. Eur J Surg Oncol 37(9): 791-797, 2011. PMID: 21741199. DOI: 10.1016/j.ejso.2011.06.008

9 Kim H, Kwon W, Kim JR, Byun Y, Jang JY and Kim SW: Recurrence patterns after pancreaticoduodenectomy for ampullary cancer. J Hepatobiliary Pancreat Sci 26(5): 179-186, 2019. PMID: 30849209. DOI: 10.1002/jhbp.618

10 Kim WS, Choi DW, Choi SH, Heo JS, You DD and Lee HG: Clinical significance of pathologic subtype in curatively resected ampulla of vater cancer. J Surg Oncol 105(3): 266-272, 2011. PMID: 21882202. DOI: $10.1002 /$ jso.22090 
11 Carter JT, Grenert JP, Rubenstein L, Stewart L and Way LW: Tumors of the ampulla of Vater: Histopathologic classification and predictors of survival. J Am Coll Surg 207(2): 210-218, 2008. PMID: 18656049. DOI: 10.1016/j.jamcollsurg. 2008.01.028

12 Feng JF, Huang Y and Chen QX: Preoperative platelet lymphocyte ratio (PLR) is superior to neutrophil lymphocyte ratio (NLR) as a predictive factor in patients with esophageal squamous cell carcinoma. World J Surg Oncol 12: 58, 2014. PMID: 24641770. DOI: 10.1186/1477-7819-12-58

13 Feng JF, Huang Y and Liu JS: Combination of neutrophil lymphocyte ratio and platelet lymphocyte ratio is a useful predictor of postoperative survival in patients with esophageal squamous cell carcinoma. Onco Targets Ther 6: 1605-1612, 2013. PMID: 24403837. DOI: 10.2147/OTT.S52501

14 Yuan D, Zhu K, Li K, Yan R, Jia Y and Dang C: The preoperative neutrophil-lymphocyte ratio predicts recurrence and survival among patients undergoing R0 resections of adenocarcinomas of the esophagogastric junction. J Surg Oncol 110(3): 333-340, 2014. PMID: 24889121. DOI: 10.1002/ jso. 23651

15 Zhang Y, Lu JJ, Du YP, Feng CX, Wang LQ and Chen MB: Prognostic value of neutrophil-to-lymphocyte ratio and platelet-to-lymphocyte ratio in gastric cancer. Medicine 97(12): e0144, 2018. PMID: 29561419. DOI:10.1097/ MD.0000000000010144

16 Hsu JT, Liao CK, Le PH, Chen TH, Lin CJ, Chen JS, Chiang $\mathrm{KC}$ and Yeh TS: Prognostic value of the preoperative neutrophil to lymphocyte ratio in resectable gastric cancer. Medicine 94(39): e1589, 2015. PMID: 26426635. DOI: 10.1097/MD.000 0000000001589

17 Chan JC, Chan DL, Diakos CI, Engel A, Pavlakis N, Gill A and Clarke SJ: The lymphocyte-to-monocyte ratio is a superior predictor of overall survival in comparison to established biomarkers of resectable colorectal cancer. Ann Surg 265(3): 539-546, 2017. PMID: 27070934. DOI: 10.1097/SLA. 0000000000001743

18 Abe S, Kawai K, Nozawa H, Hata K, Kiyomatsu T, Morikawa $\mathrm{T}$ and Watanabe T: LMR predicts outcome in patients after preoperative chemoradiotherapy for stage II-III rectal cancer. J Surg Res 222: 122-131, 2018. PMID: 29273363. DOI: 10.1016/j.jss.2017.09.053

19 Saito H, Noji T, Okamura K, Tsuchikawa T, Shichinohe T and Hirano S: A new prognostic scoring system using factors available preoperatively to predict survival after operative resection of perihilar cholangiocarcinoma. Surgery 159(3): 842-851, 2016. PMID: 26683498. DOI: 10.1016/ j.surg.2015.10.027

$20 \mathrm{Yu} \mathrm{J}$, Ding Z, Yang Y and Liu S: Increased platelet-tolymphocytes ratio is associated with poor long-term prognosis in patients with pancreatic cancer after surgery. Medicine 97(25): e11002, 2018. PMID: 29923983. DOI: 10.1097/MD.0000000 000011002

21 Asari S, Matsumoto I, Toyama H, Shinzeki M, Goto T, Ishida J, Ajiki T, Fukumoto T, Ku Y: Preoperative independent prognostic factors in patients with borderline resectable pancreatic ductal adenocarcinoma following curative resection: the neutrophillymphocyte and platelet-lymphocyte ratios. Surg Today 46(5): 583-592, 2016. PMID: 26108488. DOI: 10.1007/s00595-0151206-3
22 Qi Q, Geng Y, Sun M, Wang P and Chen Z: Clinical implications of systemic inflammatory response markers as independent prognostic factors for advanced pancreatic cancer. Pancreatology 15(2): 145-150, 2015. PMID: 25641673. DOI: 10.1016/ j.pan.2014.12.004

23 Stotz M, Gerger A, Eisner F, Szkandera J, Loibner H, Ress AL, Kornprat P, AlZoughbi W, Seggewies FS, Lackner C, Stojakovic T, Samonigg H, Hoefler G and Pichler M: Increased neutrophillymphocyte ratio is a poor prognostic factor in patients with primary operable and inoperable pancreatic cancer. Br J Cancer 109(2): 416-421, 2013. PMID: 23799847. DOI: 10.1038/ bjc. 2013.332

24 Zhou W, Rong Y, Kuang T, Xu Y, Shen X, Ji Y, Lou W and Wang D: The value of systemic inflammatory markers in identifying malignancy in mucinous pancreatic cystic neoplasms Oncotarget 8(70): 115561-115569, 2017. PMID: 29383181. DOI: 10.18632 /oncotarget.23310

25 Brierley JD, Gospodarowicz MK and Wittekind C (eds): TNM Classification of Malignant Tumours, 8th edn Oxford, UK: Wiley Blackwell, 2017.

26 Goh BK, Teo JY, Allen JC Jr, Tan DM, Chan CY, Lee SY, Tai DW, Thng CH, Cheow PC, Chow PK, Ooi LL and Chung AY: Preoperative platelet-to-lymphocyte ratio improves the performance of the international consensus guidelines in predicting malignant pancreatic cystic neoplasms. Pancreatology 16(5): 888-892, 2016. PMID: 27421563. DOI: 10.1016/ j.pan.2016.06.660

27 Chiang CY, Huang KH, Fang WL, Wu CW, Chen JH, Lo SS, Hsieh MC, Shen KH, Li AF, Niu DM and Chiou SH: Factors associated with recurrence within 2 years after curative surgery for gastric adenocarcinoma. World J Surg 35(11): 2472-2478, 2011. PMID: 21879421. DOI: 10.1007/s00268011-1247-8

28 D'Angelica M, Gonen M, Brennan MF, Turnbull AD, Bains M and Karpeh MS: Patterns of initial recurrence in completely resected gastric adenocarcinoma. Ann Surg 240(5): 808-816, 2004. PMID: 15492562. DOI: 10.1097/01.sla.0000 143245.28656.15

29 Shiraishi N, Inomata M, Osawa N, Yasuda K, Adachi Y and Kitano S: Early and late recurrence after gastrectomy for gastric carcinoma. Univariate and multivariate analyses. Cancer $89(2)$ : 255-261, 2000. PMID: 10918153. DOI: 10.1002/10970142(20000715)89:2<255::aid-cncr8>3.0.co;2-n

30 Smith RA, Bosonnet L, Ghaneh P, Sutton R, Evans J, Healey P, Garvey C, Hughes M, Raraty M, Campbell F and Neoptolemos JP: The platelet-lymphocyte ratio improves the predictive value of serum CA19-9 levels in determining patient selection for staging laparoscopy in suspected periampullary cancer. Surgery 143(5): 658-666, 2008. PMID: 18436014. DOI: 10.1016/j.surg.2007.12.014

31 Smith RA, Ghaneh P, Sutton R, Raraty M, Campbell F and Neoptolemos JP: Prognosis of resected ampullary adenocarcinoma by preoperative serum CA19-9 levels and platelet-lymphocyte ratio. J Gastrointest Surg 12(8): 1422-1428, 2008. PMID: 18543046. DOI: 10.1007/s11605-008-0554-3

32 Wang W, Liu W, Zhang N and He X: Preoperative plateletlymphocyte ratio is an independent prognostic factor in ampullary carcinoma following pancreaticoduodenectomy. Oncol Lett 16(4): 4879-4888, 2018. PMID: 30250554. DOI: $10.3892 / \mathrm{ol} .2018 .9285$ 
33 Salazar-Onfray F, López MN and Mendoza-Naranjo A: Paradoxical effects of cytokines in tumor immune surveillance and tumor immune escape. Cytokine Growth Factor Rev 18(12): 171-182, 2007. PMID: 17329145. DOI: 10.1016/ j.cytogfr.2007.01.015

34 Buergy D, Wenz F, Groden C and Brockmann MA: Tumorplatelet interaction in solid tumors. Int J Cancer 130(12): 27472760, 2012. PMID: 22261860. DOI: 10.1002/ijc.27441

35 Lin RJ, Afshar-Kharghan V and Schafer AI: Paraneoplastic thrombocytosis: the secrets of tumor self-promotion. Blood 124(2): 184-187, 2014. PMID: 24868077. DOI: 10.1182/blood2014-03-562538

36 Kim ST, Lee J, Lee KT, Lee JK, Lee KH, Choi SH, Heo JS, Choi DW, Park SH, Park JO, Lim HY, Park YS and Kang WK: The efficacy of frontline platinum-based combination chemotherapy in advanced adenocarcinoma of the ampulla of Vater. Med Oncol 27(4): 1149-1154, 2010. PMID: 19898973. DOI: $10.1007 / \mathrm{s} 12032-009-9351-4$

37 Heinemann V, Boeck S, Hinke A, Labianca R and Louvet C: Meta-analysis of randomized trials: evaluation of benefit from gemcitabine-based combination chemotherapy applied in advanced pancreatic cancer. BMC Cancer 82(8), 2008. PMID: 18373843. DOI: $10.1186 / 1471-2407-8-82$

38 Regine WF, Winter KA, Abrams RA, Safran H, Hoffman JP, Konski A, Benson AB, Macdonald JS, Kudrimoti MR, Fromm ML, Haddock MG, Schaefer P, Willett CG and Rich TA: Fluorouracil $v s$ gemcitabine chemotherapy before and after fluorouracil-based chemoradiation following resection of pancreatic adenocarcinoma: a randomized controlled trial. JAMA 299(9): 1019-1026, 2008. PMID: 18319412. DOI: 10.1001/jama.299.9.1019

39 Ghosn M, Kourie HR, El Rassy E, Haddad FG, Hanna C, El Karak F and Nasr D: Where does chemotherapy stands in the treatment of ampullary carcinoma? A review of literature. World J Gastrointest Oncol 8(10): 745-750, 2016. PMID: 27795814. DOI: $10.4251 /$ wjgo.v8.i10.745

40 Feng D, Leong M, Li T, Chen L and Li T: Surgical outcomes in patients with locally advanced gastric cancer treated with S-1 and oxaliplatin as neoadjuvant chemotherapy. World J Surg Oncol 13(11), 2015. PMID: 25634099. DOI: 10.1186/s12957015-0444-6

41 Yoshikawa T, Tanabe K, Nishikawa K, Ito Y, Matsui T, Kimura Y, Hirabayashi N, Mikata S, Iwahashi M, Fukushima R, Takiguchi N, Miyashiro I, Morita S, Miyashita Y, Tsuburaya A and Sakamoto J: Induction of a pathological complete response by four courses of neoadjuvant chemotherapy for gastric cancer: Early results of the randomized phase II COMPASS trial. Ann Surg Oncol 21(1): 213-219, 2014. PMID: 23838904. DOI: $10.1245 / \mathrm{s} 10434-013-3055-\mathrm{x}$
42 Agarwal A, Chang GJ, Hu CY, Taggart M, Rashid A, Park IJ, You YN, Das P, Krishnan S, Crane CH, Rodriguez-Bigas M, Skibber J, Ellis L, Eng C, Kopetz S and Maru DM: Quantified pathologic response assessed as residual tumor burden is a predictor of recurrence-free survival in patients with rectal cancer who undergo resection after neoadjuvant chemoradiotherapy. Cancer 119(24): 4231-4241, 2013. PMID: 24089344. DOI: $10.1002 /$ cncr.28331

43 Nagakawa Y, Sahara Y, Hosokawa Y, Murakami Y, Yamaue H, Satoi S, Unno M, Isaji S, Endo I, Sho M, Fujii T, Takishita C, Hijikata Y, Suzuki S, Kawachi S, Katsumata K, Ohta T, Nagakawa $\mathrm{T}$ and Tsuchida A: Clinical impact of neoadjuvant chemotherapy and chemoradiotherapy in borderline resectable pancreatic cancer: Analysis of 884 patients at facilities specializing in pancreatic surgery. Ann Surg Oncol 26(6): 16291636, 2019. PMID: 30610555. DOI: 10.1245/s10434-01807131-8

44 Kurahara H, Shinchi H, Ohtsuka T, Miyasaka Y, Matsunaga T, Noshiro H, Adachi T, Eguchi S, Imamura N, Nanashima A, Sakamoto K, Nagano H, Ohta M, Inomata M, Chikamoto A, Baba H, Watanabe Y, Nishihara K, Yasunaga M, Okuda K, Natsugoe $S$ and Nakamura M: Significance of neoadjuvant therapy for borderline resectable pancreatic cancer: A multicenter retrospective study. Langenbecks Arch Surg 404(2): 167-174, 2019. PMID: 30649607. DOI: 10.1007/s00423-01901754-5

45 Cloyd JM, Wang H, Overman M, Zhao J, Denbo J, Prakash L, Kim MP, Shroff R, Javle M, Varadhachary GR, Fogelman D, Wolff RA, Koay EJ, Das P, Maitra A, Aloia TA, Vauthey JN, Fleming JB, Lee JE and Katz MHG: Influence of preoperative therapy on short- and long-term outcomes of patients with adenocarcinoma of the ampulla of Vater. Ann Surg Oncol 24(7): 2031-2039, 2017. PMID: 28124275. DOI: 10.1245/s10434-0175777-7

46 Yamashita S, Overman MJ, Wang H, Zhao J, Okuno M, Goumard C, Tzeng CW, Kim M, Fleming JB, Vauthey JN, Katz MH, Lee JE and Conrad C: Pathologic response to preoperative therapy as a novel prognosticator for ampullary and duodenal adenocarcinoma. Ann Surg Oncol 24(13): 3954-3963, 2017. PMID: 28980211. DOI: 10.1245/s10434-017-6098-6
Received October 25, 2019

Revised November 4, 2019

Accepted November 5, 2019 